\title{
Plant Regeneration of Periwinkle (Catharanthus roseus) via Organogenesis
}

\author{
Andrea Swanberg ${ }^{1}$ and Wenhao Dai ${ }^{2,3}$ \\ Lofsgard, Fargo, ND 58105 \\ Additional index words. In vitro, explant, X-disease
}

Department of Plant Sciences, North Dakota State University, 374C

\begin{abstract}
Two periwinkle cultivars, Pacific Coral (P1) and Sunstorm Rose (P2), were used for development of a plant regeneration system. Leaf and internodal explants collected from in vitro plants were plated onto woody plant medium (WPM) using a factorial arrangement of 6-benzyladeine (BA) and 1-naphthalene acetic acid (NAA). Shoots were successfully regenerated. Shoot production from leaf tissues was minimal for all cultivars, whereas internodal tissues showed variable rates of regeneration depending on the hormone combination. Cultivar P1 showed the maximum regeneration rate (73.3\%) when internodal explants, 4 to $6 \mathrm{~mm}$ in length, were placed on WPM containing $5 \mu_{M}$ BA and $5 \mu_{M}$ NAA. Cultivar P2 showed a regeneration rate of $56.7 \%$ with a combination of $20 \mu \mathrm{M}$ BA and $10 \mu \mathrm{M}$ NAA. Shoot regeneration rate increased as the internodal explant size increased for $\mathrm{P} 2$; however, the regeneration rate decreased when the explant size was greater than $7 \mathrm{~mm}$ for $P 1$. The shoot regeneration rate decreased as the period of the dark treatment of internodal explants increased in both P1 and P2. The antibiotics carbenicillin (Carb) and cefotaxime (Cef) had little effect on shoot regeneration. There was a slightly higher rate observed for $P 1$ when Cef was added into the medium, whereas P2 showed a decrease with the addition of Cef. Carb showed no significant effect on shoot regeneration for both cultivars. Addition of both Carb and Cef to the medium slightly inhibited shoot regeneration.
\end{abstract}

Periwinkle (Catharanthus roseus), a member of the Apocynaceae family, is highly valued in the horticultural industry. A native to Madagascar, this herbaceous plant grows to $\approx 80 \mathrm{~cm}$ high and blooms continuously year-round with pink, purple, or white flowers (Hogan, 2003). Study of periwinkle has increased because of its ability to produce secondary metabolites such as terpenoid indole alkaloids that may be used to treat cardiac diseases and certain tumors in mammals (Favali et al., 2004). Periwinkle is also a natural host of many phytoplasmas. Phytoplasmas are cell wall-less organisms that infect over 300 plant species, including many woody species. They thrive in the phloem of infected plants and can cause symptoms such as curled and yellow leaves, witches-broom appearance, and phyllody, resulting in reduced crop yield and plant death (Lee et al., 2000). One phytoplasma disease, called $\mathrm{X}$-disease, causes severe damage on many

\footnotetext{
Received for publication 4 Jan. 2008. Accepted for publication $20 \mathrm{Feb} .2008$.

This research was supported in part by McIntireStennis Project ND06212 and USDA-CSREES2005-35300-15457.

We thank Drs. T. Adhikari, E. Berry, and E. Deckard for their valuable suggestions and comments when we were preparing the manuscript. ${ }^{1}$ Graduate student.

${ }^{2}$ Assistant Professor.

${ }^{3}$ To whom reprint requests should be addressed; e-mailwenhao.dai@ndsu.edu
}

Prunus species such as sweet and sour cherries, peach, nectarine, and chokecherry (Guo et al., 1996). Periwinkle is a small, relatively fast-growing plant, making it an ideal species for the study of pathogen-host interaction of phytoplasma. Development of an efficient transformation system used for testing genes is important to elucidate the function of future-cloned resistant genes and interaction between phytoplasma and plant hosts.

A regeneration system is a prerequisite for recovering transgenic plants. Many factors, including genotype (Choi et al., 2004; Obukosia et al., 2005; Xu et al., 2007), medium (Trigiano and Gray, 2000), explant type (Gambino et al., 2007), plant growth regulator (PGR) (Trigiano and Gray, 2000), and culture condition (Choi et al., 2001), can affect plant regeneration.

Periwinkle organogenesis was first reported in the late 1970 s by Dhruva et al. (1977) followed by Ramavat et al. (1978) and Abou-Mandour et al. (1979). However, the shoot regeneration rate was low. In 1989 , Mollers and Sarkar induced calluses from phytoplasma-infected stem tissues. These callus tissues differentiated into plants on the MS medium with $0.25 \mathrm{mg} \cdot \mathrm{L}^{-1}$ 6-benzyladeine (BA), $1.0 \mathrm{mg} \cdot \mathrm{L}^{-1} 1$-naphthalene acetic acid (NAA), and $10.0 \mathrm{mg} \cdot \mathrm{L}^{-1}$ gentamicin. Further test confirmed that phytoplasmas were eliminated. Recently, efficient plant generation of periwinkle was accomplished mainly through somatic embryogenesis starting with generative tissues such as anthers and immature zygotic embryos. Kim et al. (1994) induced somatic embryos from calluses derived from anthers in MS medium supplemented with $1.0 \mathrm{mg} \cdot \mathrm{L}^{-1} \mathrm{NAA}$ and 0.1 $\mathrm{mg} \cdot \mathrm{L}^{-1}$ kinetin. Plants were also regenerated from immature zygotic embryos in 2, 4-D containing MS medium through a callusing phase (Kim et al., 2004). An efficient somatic embryogenesis system has been established. Embryogenic calluses were developed from hypocotyls and primary cotyledonary somatic embryos and somatic embryos were then differentiated on medium supplemented with $1.0 \mathrm{mg} \cdot \mathrm{L}^{-1} \mathrm{NAA}$ and $1.5 \mathrm{mg} \cdot \mathrm{L}^{-1} \mathrm{BA}$ (Junaid et al., 2007). However, the relatively high regeneration rate published was achieved through somatic embryogenesis and only one cultivar was used.

The objective of this research was to determine factors such as PGR, genotype, explant, dark treatment, and antibiotics that influence plant regeneration ability of periwinkle. Such data are essential for the successful development of an efficient plant regeneration system for Agrobacteriummediated transformation in this species.

\section{Materials and Methods}

Plant material. Seeds of two periwinkle cultivars, Pacific Coral and Sunstorm Rose, were purchased from Syngenta Seeds (Downers Grove, IL) and denoted P1 and $\mathrm{P} 2$, respectively. Seeds were sterilized with $70 \%$ ethanol for $2 \mathrm{~min}$ and a $20 \%$ bleach solution for $15 \mathrm{~min}$, followed by five washes with sterile water, and then placed on filter paper in a petri dish for germination. Seedlings at the four-leaf stage were transferred to a petri dish containing MS medium (Murashige and Skoog, 1962) supplemented with $30 \mathrm{~g} \cdot \mathrm{L}^{-1}$ sucrose and $6.5 \mathrm{~g} \cdot \mathrm{L}^{-1}$ agar (\#0140-01-0; Difco Co., Detroit, MI). The medium $\mathrm{pH}$ was adjusted to 5.7 to 5.8 before autoclaving. After growth of seedlings for 2 weeks, four shoot tips were cut and placed in $100-\mathrm{mL}^{-1}$ baby food jars containing MS medium supplemented with $2.5 \mu \mathrm{M}$ BA and $0.5 \mu \mathrm{M}$ gibberellic acid for shoot proliferation. All in vitro cultures were maintained in a culture room with a $16 / 8$-h photoperiod at $21{ }^{\circ} \mathrm{C}$ and subcultured every 4 weeks.

Plant regeneration. Experiments were conducted to determine factors affecting plant regeneration of periwinkle cultivars. Unless otherwise stated, all basal regeneration media were woody plant medium (WPM) (Lloyd and McCown, 1980) supplemented with $20 \mathrm{~g} \cdot \mathrm{L}^{-1}$ sucrose and $6.5 \mathrm{~g} \cdot \mathrm{L}^{-1}$ agar, and the $\mathrm{pH}$ was adjusted to 5.2 before autoclaving.

1. Effects of genotype, explant, and PGR on plant regeneration. Two types of explants (internode and leaf) of cultivars P1 and P2 were tested for plant regeneration in different media. Fourweek-old in vitro shoots were used for explant preparation. Internodes were cut to 4 to $6 \mathrm{~mm}$ long and leaves were 
cut into 10- to 14-mm long segments. After collection was complete, explants of each cultivar and tissue type were gently mixed. The internodes were placed horizontally and the leaf segments were placed with the abaxial side up on $25 \mathrm{~mL}$ regeneration medium in $100 \times 15-\mathrm{mm}$ petri dishes sealed with parafilm and placed under a 16/8-h photoperiod at $21{ }^{\circ} \mathrm{C}$. Each dish contained five internodal and five leaf segments and each treatment contained three dishes. This experiment was conducted as a completely randomized design (CRD) consisting of two replications of a $2 \times 2 \times 2 \times 4 \times 5$ factorial arrangement with cultivars (P1 and P2), explant types (internode and leaf), PGRs (BA and NAA), and PGR concentrations (NAA at $0,1,5$, or $10 \mu \mathrm{M}$ and BA at $0,1,5,10$, or $20 \mu \mathrm{M}$ ), respectively.

2. Effect of explant size on plant regeneration. The internodes of $\mathrm{P} 1$ and $\mathrm{P} 2$ were cut into four size ranges (treatment): 1 to $3 \mathrm{~mm}, 3$ to $5 \mathrm{~mm}, 5$ to $7 \mathrm{~mm}$, and 7 to $9 \mathrm{~mm}$ in length. Each treatment consisted of three dishes and 10 internodal explants per plate. The optimal regeneration medium was WPM with $5 \mu \mathrm{M}$ NAA and $5 \mu \mathrm{M}$ BA for P1 and $10 \mu \mathrm{M}$ NAA and $20 \mu \mathrm{M}$ BA for P2. The plates were sealed with parafilm and incubated in a culture room with a 16/8-h photoperiod at $21{ }^{\circ} \mathrm{C}$. This experiment was also conducted as a CRD consisting of two replications of a $2 \times 4$ factorial arrangement of cultivar and explant size, respectively.

3. Effect of dark treatment on plant regeneration. Internodal explants, 4 to $6 \mathrm{~mm}$ in length, were placed onto the optimal regeneration media described previously. Each treatment consisted of three plates and 10 explants in each plate. The plates were sealed with parafilm and placed in a dark drawer for 0-, 1-, 2-, and 3-week periods. After the dark period ended, the plates were moved to a culture room at a $16 / 8$-h photoperiod at $21^{\circ} \mathrm{C}$. The experiment was set up as a CRD with two replications of a factorial arrangement with a $2 \times 4$ of cultivar and dark period, respectively.

4. Effect of antibiotics on plant regeneration. The effect of antibiotics on adventitious shoot formation was evaluated by supplementing the regeneration medium with antibiotics carbenicillin (Carb) and cefotaxime (Cef). Internodes, 4 to $6 \mathrm{~mm}$ in length, were placed onto the optimal regeneration media described previously. Four treatments were included in this experiment: no antibiotics, $500 \mathrm{mg} \cdot \mathrm{L}$ Carb, $250 \mathrm{mg} \cdot \mathrm{L}^{-1}$ Cef, and a combination of $500 \mathrm{mg} \cdot \mathrm{L}^{-1}$ Carb and $250 \mathrm{mg} \cdot \mathrm{L}^{-1} \mathrm{Cef}$. The effect of antibiotic was tested as a CRD consisting of two replications of a factorial arrangement with a $2 \times 4$ of cultivar and antibiotic treatment, respectively.
For all regeneration experiments, the number of explants producing shoots and callus size were recorded after 1 month from the beginning of the experiment. The cultures were subcultured on the fresh medium every 4 weeks and data were again recorded after the second month.

Rooting and acclimation. The response of in vitro cuttings of periwinkle to auxin (NAA) was tested. Four microcuttings (greater than $1.5 \mathrm{~cm}$ ) were prepared from 4week-old in vitro plants of regenerated P1 and placed into a baby food jar containing 25 $\mathrm{mL}$ MS medium with various concentrations of NAA. The in vitro rooting experiment was repeated twice and conducted as a CRD with three treatments: no NAA, $0.5 \mu \mathrm{M}$ NAA, and $5.0 \mu \mathrm{M}$ NAA. The number of cuttings rooted and the number of roots per responding cutting were recorded. The physical appearance of the roots was also noted. Rooted plants were then transplanted into a flat filled with moist Sunshine mix (Sun Gro Horticulture Canada Ltd., Seba Beach, AB, Canada) and covered with a clear plastic top for acclimation. After 1 week, the top was gradually removed and the surviving plants were potted and maintained in a greenhouse.

Statistical analysis. Data from all experiments were subject to analysis of variation and mean comparison using the GLM procedure of SAS software Version 9.1 (SAS Institute, 2004).

\section{Results}

Effects of genotype, explant, and plant growth regulator on plant regeneration. Cal-
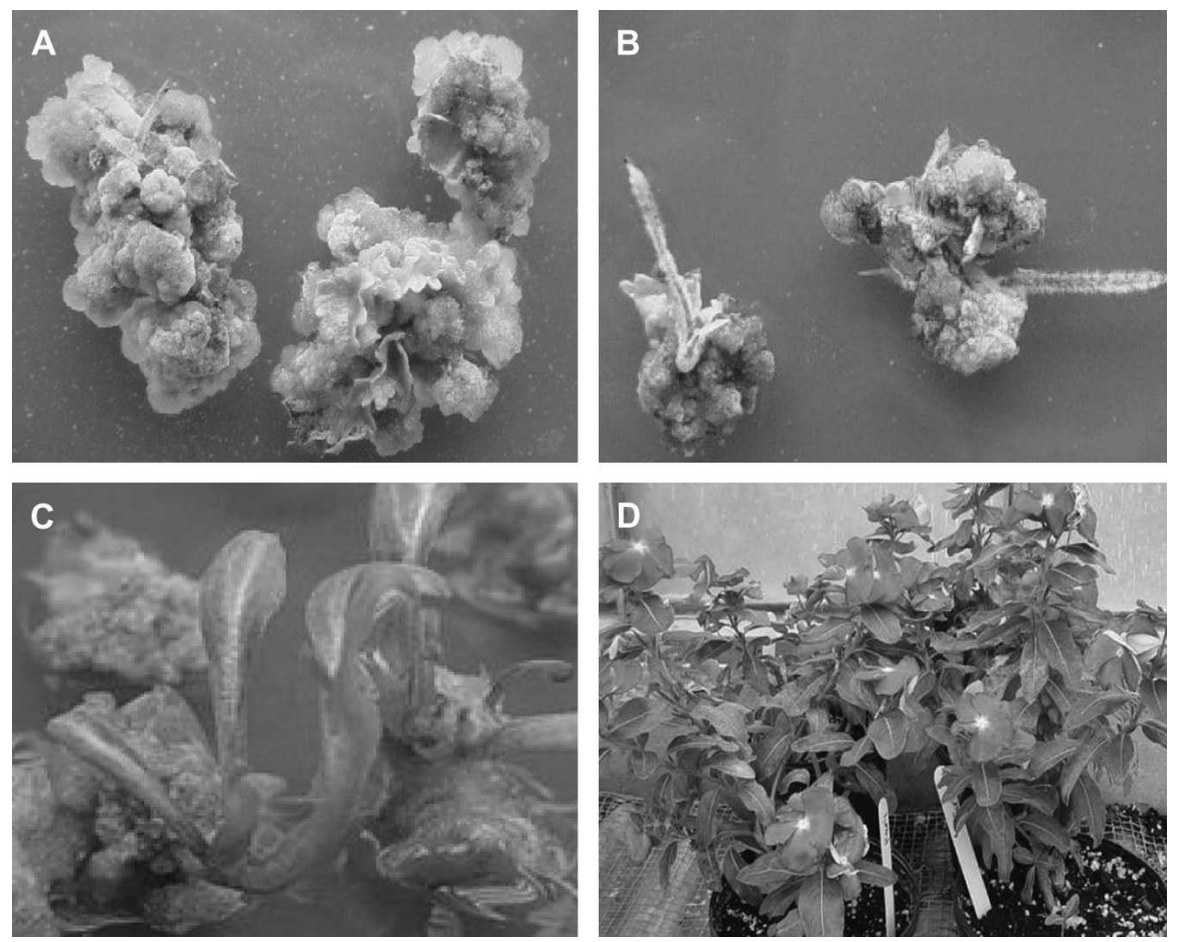

Fig. 1. In vitro plant regeneration of periwinkle. (A) Calluses developed from leaf and internodal tissues; (B) adventitious roots formed from callus tissues; (C) shoots regenerated from internodal explants; (D) regenerated periwinkle plants were blooming in the greenhouse.

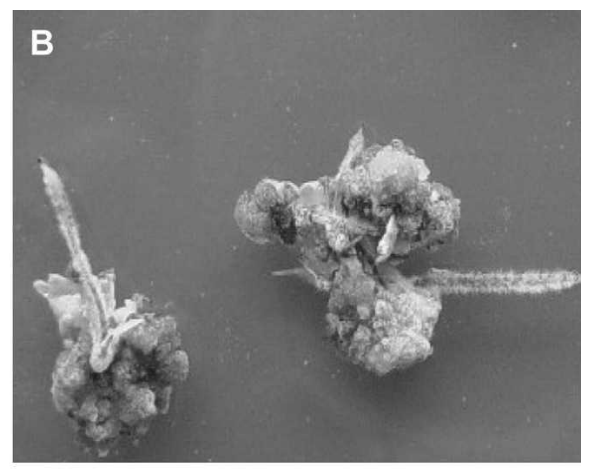

luses developed from both leaf and internodal explants of all cultivars when cultured on WPM with PGRs (Fig. 1A). The highest percent of callus formation $(100 \%)$ occurred on the media containing both BA and NAA regardless of the concentration. As the $\mathrm{BA}$ concentration was lowered, callus size decreased. Lowering the ratio of BA to NAA, adventitious roots developed from both leaf and internodal explants (Fig. 1B). Leaf and internodal tissues generated callus that appeared identical in color, texture, and size. The appearance was green and dense, sometimes with very swollen explant tissue remaining. The size of callus was $\approx 4$ to $9 \mathrm{~mm}$ in diameter during the first month; and after the second month, most calli increased to greater than $10 \mathrm{~mm}$ in diameter.

Analysis of variance indicated most factors were significant among P1 and P2 (Table $1)$. Both cultivars showed limited regeneration from leaf tissues and the regeneration rate was significantly lower than observed from internodal tissues. Significant interactions were determined among these factors except the ones among cultivar, BA, and explant.

In general, shoots were generating during the second month when explants with calluses were subcultured in the new medium (Fig. 1C). Internodal explants of both cultivars had significantly higher rates of shoot formation than those of leaf explants (Table 2).

Shoot regeneration was found to be PGR $2)$. The maximum regeneration rate $(73.3 \%)$ was achieved from P1 when internodes were 
placed on WPM containing $5 \mu \mathrm{M}$ BA and $5 \mu \mathrm{M}$ NAA, whereas $56.7 \%$ of internodal explants of P2 produced shoots on WPM with $20 \mu \mathrm{M}$ BA and $10 \mu \mathrm{M}$ NAA. These data indicated that determination of optimal PGR concentration was vital before conducting further experiments on shoot regeneration of periwinkle.

Effect of explant size on plant regeneration. The size of the initial internodal explant affected the regeneration rate (Fig. 2). The effect of explant size was also found to be genotype-dependent. For P1, no shoot regeneration occurred if the internode size was less than $3 \mathrm{~mm}$ long; however, shoot regeneration was significantly greater in 3- to 5-mm to 5- to 7-mm long explants.

Effect of dark treatment on plant regeneration. The shoot regeneration rate in both P1 and P2 was significantly lower when internode cultures were kept in the dark for a range of 1 to 3 weeks than those in the regular photoperiod (16/8 h) condition (Fig. 3). For $\mathrm{P} 1$, the average number of shoots regenerated per treatment decreased significantly after 1 week of dark treatment (data not shown). Two and 3 weeks in the dark completely inhibited shoot formation. P2 also showed a decrease in regeneration rate as the time of cultures in the dark increased. However, dark treatment seemed to have less effect on P2 compared with P1.

Effect of antibiotics on plant regeneration. Periwinkle cultivars $\mathrm{P} 1$ and $\mathrm{P} 2$ responded to antibiotics Carb and Cef (Fig. 4) differently; however, the difference among treatments was not significant. Addition of Cef to the plant regeneration medium increased the shoot regeneration rate from $44 \%$ to $54.5 \%$ for P1, but slightly decreased the shoot regeneration for P2 from $29 \%$ to $20 \%$. Carbenicillin had no significant effect on shoot regeneration for both cultivars. Addition of Cef and Carb together inhibited shoot regeneration of both cultivars (Fig. 4).

Rooting and acclimatization. In vitro cuttings of regenerated periwinkle plants rooted easily. The highest rooting rate was $100 \%$ for the shoots grown in $5.0 \mu \mathrm{M}$ NAA and produced roots that were shorter and thicker than normal roots. In the treatment with $0.5 \mu \mathrm{M}$ NAA, the roots formed at a rate of $90.6 \%$ and roots were healthy and strong in appearance. Approximately $47 \%$ of in vitro cuttings developed roots even in auxin-free medium. Rooted plants were transplanted in potting mix and acclimatized under ambient condition. An average of $60 \%$ of the rooted plants survived in the greenhouse and bloomed in 2 to 3 months (Fig. 1D).

\section{Discussion}

It is well known that the balance of cytokinin and auxin in plant tissues controls the direction of organogenesis (Skoog and Miller, 1957). To keep this balance ideal for development of new organs, exogenous cytokinin or auxin is usually added to the plant regeneration medium. In this research, leaf and internodal tissues of periwinkle were
Table 1. Results of analysis of variance on shoot regeneration of P1 and P2 periwinkle cultivars. ${ }^{\mathrm{z}}$

\begin{tabular}{lcrr}
\hline Source of variation & Degrees of freedom & Mean square & F value \\
\hline Cultivar & 1 & 1.02 & 0.93 \\
NAA & 3 & 56.98 & $52.14^{*}$ \\
BA & 4 & 33.04 & $30.23^{*}$ \\
Explant & 1 & 165.76 & $151.66^{*}$ \\
Cultivar $\times$ NAA & 3 & 63.00 & $57.64^{*}$ \\
Cultivar $\times$ BA & 4 & 2.01 & 1.84 \\
Cultivar $\times$ explant & 1 & 0.30 & 0.28 \\
NAA $\times$ BA & 12 & 12.68 & $11.6^{*}$ \\
NAA $\times$ explant & 3 & 43.17 & $39.49^{*}$ \\
BA $\times$ explant & 4 & 30.32 & $27.74^{*}$ \\
Cultivar $\times$ NAA $\times$ BA & 12 & 7.33 & $6.71^{*}$ \\
Cultivar $\times$ NAA $\times$ explant & 3 & 47.30 & $43.28^{*}$ \\
Cultivar $\times$ BA $\times$ explant & 4 & 0.58 & 0.53 \\
NAA $\times$ BA $\times$ explant & 12 & 8.84 & $8.09^{*}$ \\
Cultivar $\times$ NAA $\times$ BA $\times$ explant & 12 & 5.24 & $4.8^{*}$ \\
\hline
\end{tabular}

zP1: Pacific Coral; P2: Sunstorm Rose.

${ }^{\mathrm{y}} \mathrm{NAA}=$ naphthalene acetic acid; BA $=6$-benzyladeine.

* Significant at $P \leq 0.05$.

Table 2. Effects of genotype, explant type, and plant growth regulator on shoot regeneration of periwinkle. ${ }^{z}$

\begin{tabular}{|c|c|c|c|c|c|}
\hline \multirow[b]{3}{*}{ NAA $(\mu M)^{x}$} & \multirow[b]{3}{*}{ BA $(\mu \mathrm{M})$} & \multicolumn{4}{|c|}{ Regeneration rate ${ }^{\mathrm{y}}$} \\
\hline & & \multicolumn{2}{|c|}{ Pacific Coral (P1) } & \multicolumn{2}{|c|}{ Sunstorm Rose (P2) } \\
\hline & & Leaf & Internode & Leaf & Internode \\
\hline \multirow[t]{5}{*}{0} & 0 & 0 & 3.3 & 0 & 0 \\
\hline & 1 & 0 & 0 & 0 & 0 \\
\hline & 5 & 0 & 3.3 & 0 & 3.3 \\
\hline & 10 & 0 & 0 & 3.3 & 0 \\
\hline & 20 & 0 & 0 & 0 & 0 \\
\hline \multirow[t]{5}{*}{1} & 0 & 0 & 3.3 & 0 & 3.3 \\
\hline & 1 & 0 & 16.7 & 3.3 & 0 \\
\hline & 5 & 0 & 20 & 0 & 0 \\
\hline & 10 & 3.3 & 16.7 & 3.3 & 0 \\
\hline & 20 & 0 & 0 & 0 & 0 \\
\hline \multirow[t]{5}{*}{5} & 0 & 3.3 & 16.7 & 0 & 0 \\
\hline & 1 & 0 & 16.7 & 0 & 6.7 \\
\hline & 5 & 3.3 & 73.3 & 0 & 40 \\
\hline & 10 & 6.7 & 53.3 & 0 & 36.7 \\
\hline & 20 & 3.3 & 26.7 & 6.7 & 0 \\
\hline \multirow[t]{5}{*}{10} & 0 & 0 & 0 & 0 & 10 \\
\hline & 1 & 0 & 0 & 0 & 26.7 \\
\hline & 5 & 0 & 3.3 & 3.3 & 52.7 \\
\hline & 10 & 3.3 & 0 & 3.3 & 50 \\
\hline & 20 & 0 & 0 & 23.3 & 56.7 \\
\hline LSD & & & 1.044 & & \\
\hline
\end{tabular}

${ }^{\mathrm{z} B a s i c}$ regeneration medium: woody plant medium.

${ }^{\mathrm{y}}$ The regeneration rate is expressed as the percentage of explants forming shoots after 8 weeks (two subcultures) in vitro culture.

${ }^{\mathrm{x}} \mathrm{NAA}=$ naphthalene acetic acid; $\mathrm{BA}=6$-benzyladeine.

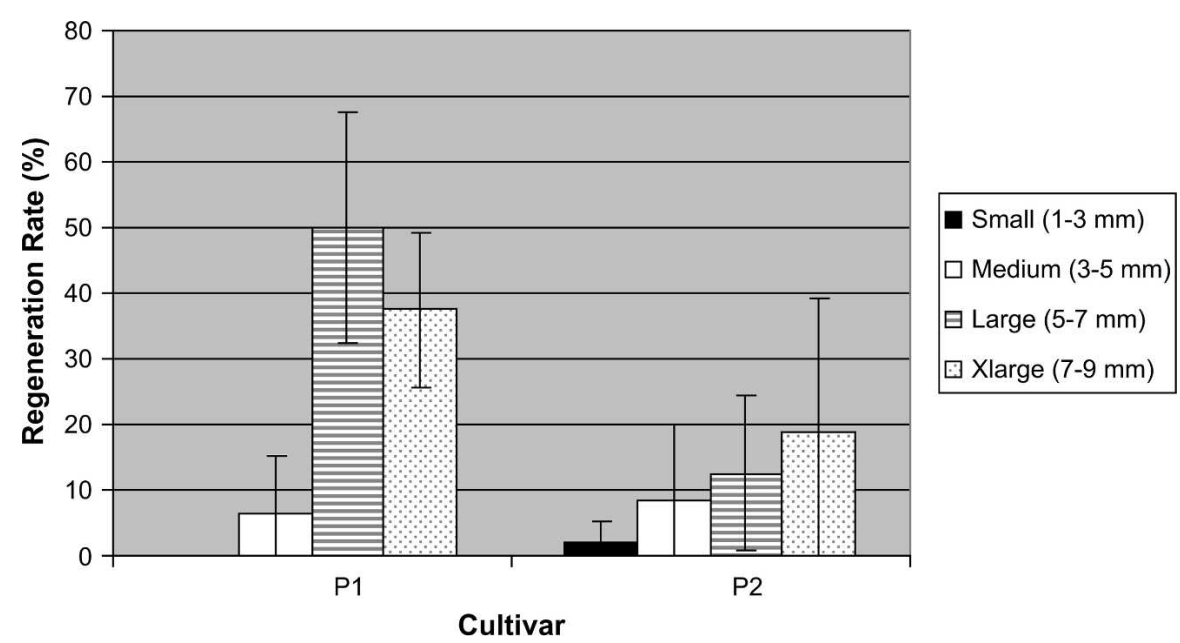

Fig. 2. The effect of explant size on shoot regeneration of periwinkle cultivars 'Pacific Coral' (P1) and 'Sunstorm Rose' (P2) $(P \leq 0.05)$. 


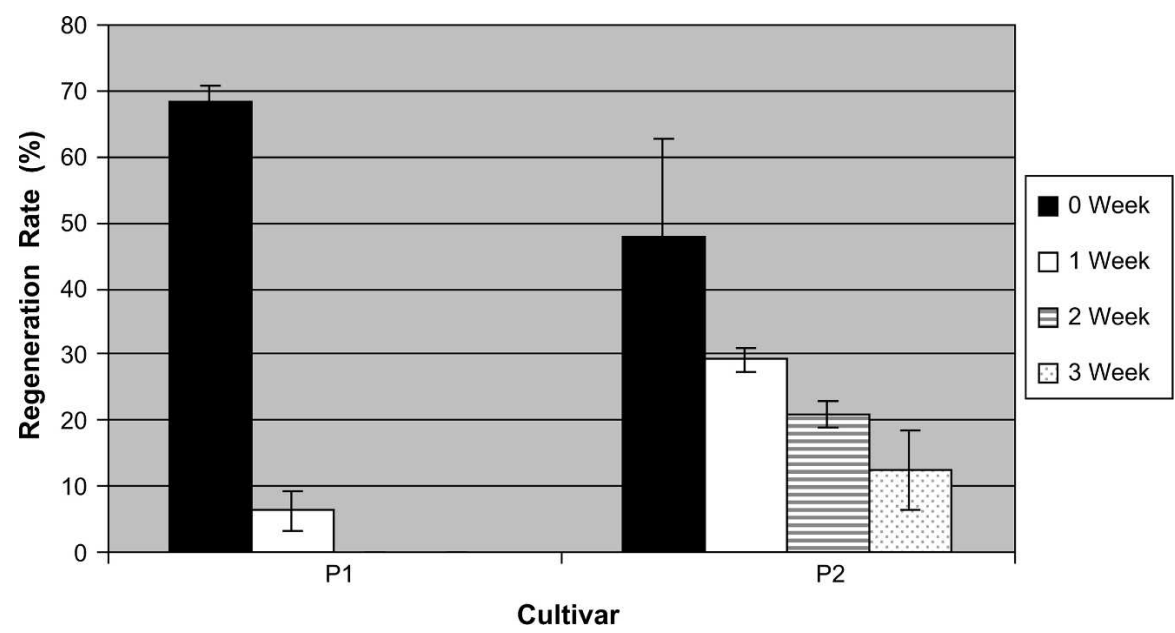

Fig. 3. The effect of dark treatment on shoot regeneration of periwinkle cultivars 'Pacific Coral' (P1) and 'Sunstorm Rose' (P2) $(P \leq 0.05)$.

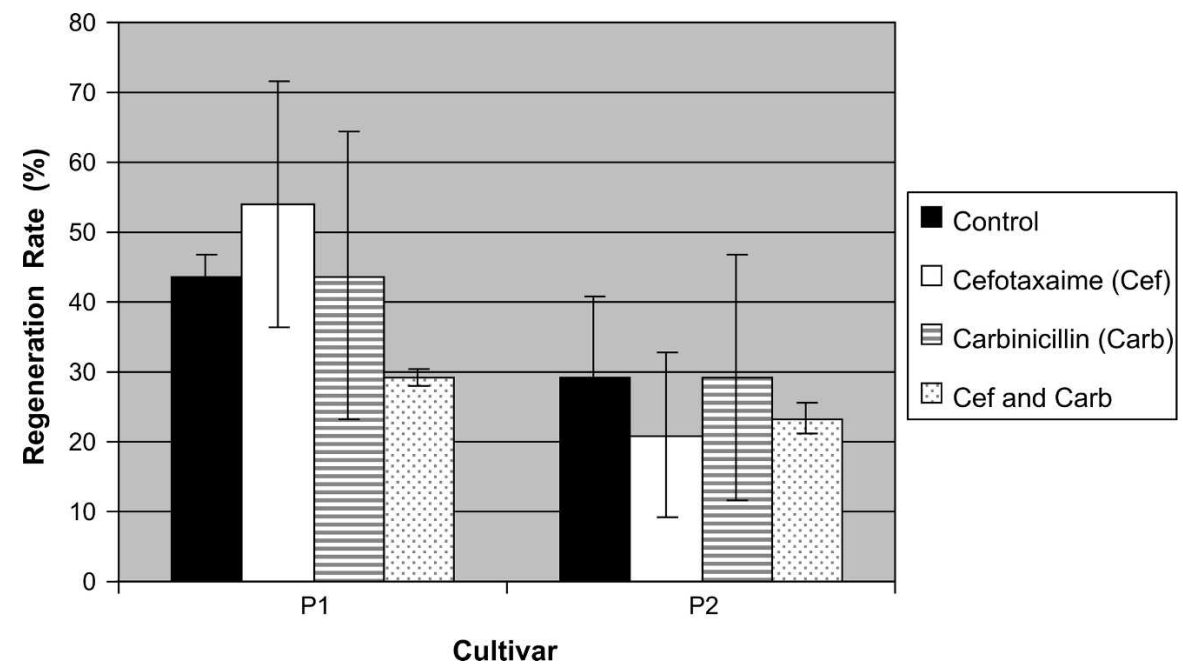

Fig. 4. The effect of antibiotics carbenicillin and cefotaxime on shoot regeneration of periwinkle cultivars 'Pacific Coral' (P1) and 'Sunstorm Rose' (P2) $(P \leq 0.05)$.

found to be sensitive to the presence and concentration of cytokinin and auxin. The ratio of cytokinin to auxin seemed critical for both callus and shoot regeneration. Periwinkle plants contain endogenous hormones and their effects were visible through callus production on hormone-free plants. However, the naturally occurring hormones in periwinkle tissues were not able to induce shoot formation. Addition of exogenous PGRs to the medium was necessary for plant regeneration of periwinkle as was found in other plant species such as chokecherry, black cherry, and gerbera (Dai et al., 2004; Espinosa et al., 2006; Kumar et al., 2004)

Plant regeneration is a challenge for Catharanthus roseus, especially through organogenesis using vegetative tissues. After testing numerous concentrations of BA and NAA as well as different cultivars and explant types, we found that variations in regeneration capabilities were caused by many factors, especially genotype and explant. This research showed that among leaf and internode tissues in this research and

published examining the effect of explant size on shoot formation. Explant size may correlate to age, because the largest internodes ( 7 to $9 \mathrm{~mm}$ ) were mostly obtained from the mid to bottom sections of the stem. Nhut et al. (2007) reported that as the bud age of gerbera increased, the regeneration capability significantly increased. The researchers cited that not only was the physiological state different between the buds, but the size probably played some role because the larger tissues had more nutrient reserves, which can promote more shoot development (Nhut et al., 2007).

Keeping the explants in the dark enhanced organogenesis was evidenced in other species
(Choi et al., 2001; Dai and Castillo, 2007; Dai et al., 2004). It is not successful in this research. Few have reported on the cause of an increased regeneration rate after a dark treatment. The dark can cause the tissue to become etiolated, which is associated with thin cell walls and a decrease in cell wall deposition (Herman and Hess, 1963). This may assist the exogenous hormones in entering the cell, speeding up the process of organogenesis. Also, some hormones such as indole acetic acid (IAA) may be better able to persist in the dark because they are lightsensitive.

In this research, addition of antibiotics to the regeneration medium had a nonsignificant but differential effect on shoot regeneration of periwinkle. Typically, Carb and Cef are used in regeneration media to suppress growth of Agrobacterium with a minimal effect on plant tissues. However, research found the addition of Carb and Cef enhanced plant regeneration in many plant species. Durum wheat, apple, and maize have each shown increased regeneration rates when Cef was added to the medium (Borrelli et al., 1992; Danilova and Dolgikh, 2004; Yepes and Aldwinckle, 1994). However, some species have demonstrated inhibition of growth or no effect with the addition of Cef, including common snapdragon, tobacco, and poplar (Ding et al., 2006; Holford and Newbury, 1992; Nauerby et al., 1997). Medium containing Carb been reported to lower the regeneration rate in apple but increase callus development in tobacco and apple (Nauerby et al., 1997; Yepes and Aldwinckle, 1994). Clearly, the effect of each antibiotic is contrasting, as discovered in this study, showing genotype (cultivar)-specific response. It has been suggested that Carb may have an auxinlike effect because it can be broken by phenylacetic acid and phenylmalonic acid, two molecules that have auxin-like behavior in tissue culture (Holford and Newbury, 1992).

In conclusion, an efficient regeneration system through organogenesis using vegetative tissues was developed. Effects of several factors, including genotype, explant (type and size), antibiotics, and dark treatment, on plant regeneration of periwinkle were elucidated, which will largely facilitate developing an efficient and universal genetic transformation system for periwinkle species.

\section{Literature Cited}

Abou-Mandour, A., S. Fischer, and F. Czygan. 1979. Regeneration of intact plants from haploid and diploid callus cells of Catharanthus roseus Z. Pflanzen-physiol Bot. 91:83-88.

Borrelli, G., N. Fonzo, and E. Lupotto. 1992. Effects of cefotaxime on callus culture and plant regeneration in durum wheat. J. Plant Physiol. 140:372-374.

Choi, J., H. Kim, J. Lee, Y. Bae, Y. Chung, J. Shin, and N. Hyung. 2001. Efficient and simple plant regeneration via organogenesis from leaf segment cultures of persimmon (Diospyros kaki Thunb.). In Vitro Cell. Dev. Biol. Plant 37:274-279.

Choi, P., Y. Kim, K. Choi, H. Chung, D. Choi, and J. Liu. 2004. Plant regeneration from hairy-root 
cultures transformed by infection with Agrobacterium rhizogenes in Catharanthus roseus. Plant Cell Rep. 22:828-831.

Dai, W. and C. Castillo. 2007. Factors affecting plant regeneration from leaf tissues of Buddleia species. HortScience 42:1670-1673.

Dai, W., V. Jacques, J. Walla, and Z. Cheng. 2004. Plant regeneration of chokecherry (Prunus virgininana L.) from in vitro leaf tissues. J. Environ. Hort. 22:225-228.

Danilova, S. and Y. Dolgikh. 2004. The stimulatory effect of the antibiotic cefotaxime on plant regeneration in maize tissue culture. Russ. J. Plant Physiol. 51:559-562.

Dhruva, B., T. Ramakrishnan, and C. Vaidyanthan. 1977. Studies in Catharanthus roseus callus cultures, callus initiation and differentiation. Curr. Sci. 46:364-365.

Ding, X., W. Chen, and Z. Du. 2006. Effects of antibiotics on plantlet regeneration via organogenesis in Populus euphratica. For. Stud. China. 8:27-31.

Espinosa, A., P. Pijut, and C. Michler. 2006. Adventitious shoot regeneration and rooting of Prunus serotina in vitro cultures. HortScience 41:193-201.

Favali, M., R. Muestti, S. Benvenuti, A. Bianchi, and L. Pressacco. 2004. Catharanthus roseus L. plants and explants infected with phytoplasmas: Alkaloid production and structural observations. Protoplasma 223:45-51.

Gambino, G., P. Ruffa, R. Vallania, and I. Gribaudo. 2007. Somatic embryogenesis from whole flowers, anthers, and ovaries of grapevine (Vitis spp.). Plant Cell Tissue Organ Cult. 90:79-83.

Guo, Y.H., J.A. Walla, Z.M. Cheng, and I.M. Lee. 1996. X-disease confirmation and distribution in chokecherry in North Dakota. Plant Dis. 80:95-102.
Hogan, S. 2003. Flora: A gardener's encyclopedia. Timber Press, Inc., Portland, OR.

Herman, D. and C. Hess. 1963. The effect of etiolation upon the rooting of cuttings. Proc. Intl. Plant Propagators's Soc. 13:42-62.

Holford, P. and H. Newbury. 1992. The effects of antibiotics and their breakdown products on the in vitro growth of Antirrhinum majus. Plant Cell Rep. 11:93-96.

Junaid, A., A. Mujib, M. Sharma, and W. Tang. 2007. Growth regulators affect primary and secondary somatic embryogenesis in Madagaskar periwinkle [Catharanthus roseus (L.) G Don] at morphological and biochemical levels. Plant Growth Regulat. 51:271-281.

Kim, S.W., S. Dong, P. Choi, and R. Jang. 2004. Plant regeneration from immature zygotic embryo-derived embryogenic calluses and cell suspension cultures of Catharanthus roseus. Plant Cell Tissue Organ Cult. 76:131-135.

Kim, S.W., K. Jung, N. Song, S. Kwak, and J. Liu. 1994. High frequency plant regeneration from anther-derived cell suspension cultures via somatic embryogenesis in Catharanthus roseus. Plant Cell Rep. 13:319-322.

Kumar, S., J. Kanwar, and D. Sharma. 2004. In vitro regeneration of Gerbera jamesonii Bolus from leaf and petiole explants. J. Plant Biochem. Biotechnol. 13:73-75.

Lee, I.M., R.E. Davis, and D.E. Gunderson-Rindal. 2000. Phytoplasma: Phytopathogenic mollicutes. Annu. Rev. Microbiol. 54:221-255.

Lloyd, G. and B. McCown. 1980. Commerciallyfeasible micropropagation of mountain laurel, Kalmia latifolia, by use of shoot-tip culture. Proc. Intl. Plant Prop. Soc. 30:421-427.

Mollers, C. and S. Sarkar. 1989. Regeneration of healthy plants from Catharanthus roseus infected with mycoplasma-like organisms through callus culture. Plant Sci. 60:83-89.
Murashige, T. and F. Skoog. 1962. A revised medium for rapid growth and bioassays with tobacco tissue cultures. Physiol. Plant. 15:473497.

Nauerby, B., K. Billing, and R. Wyndaele. 1997. Influence of the antibiotic timentin on plant regeneration compared to carbenicillin and cefotaxime in concentrations suitable for elimination of Agrobacterium tumefaciens. Plant Sci. 123:169-177.

Nhut, D., T. An, N. Huong, N. Don, N. Hai, N. Thien, and N. Vu. 2007. Effect of genotype, explant size, position, and culture medium on shoot generation of Gerbera jamesonii by receptacle transverse thin cell layer culture. Sci. Hort. 111:146-151.

Obukosia, S., E. Kimani, K. Waithaka, E. Mutitu, and P. Kimani. 2005. Effects of growth regulators and genotypes on pyrethrum in vitro. In Vitro Cell. Dev. Biol. Plant 41:162-166.

Ramavat, K., R. Rajbhansli, and H. Arya. 1978. Shoot formation in Catharanthus roseus (L.) G. Don callus cultures. Curr. Sci. 77:93-94.

SAS Institute. 2004. SAS/STAT 9.1 user's guide. SAS Institute Inc., Cary, NC.

Skoog, F. and C.O. Miller. 1957. Chemical regulation of growth and organ formation in plant tissues cultured in vitro. Symp. Soc. Exp. Biol. 11:118-140.

Trigiano, R. and D. Gray. 2000. Plant tissue culture concepts and laboratory exercises. CRC Press, Boca Raton, FL.

$\mathrm{Xu}, \mathrm{L} ., \mathrm{G}$. Liu, and M. Bao. 2007. Adventitious shoot regeneration from in vitro leaves of Formosan sweetgum (Liquidambar formosana L.). HortScience 42:721-723.

Yepes, L. and H. Aldwinckle. 1994. Factors that affect leaf regeneration efficiency in apple, and effect of antibiotics in morphogenesis. Plant Cell Tissue Organ Cult. 37:257-269. 